\title{
Don Hellison's Life and Legacy: Concluding Thoughts
}

\author{
David S. Walsh \\ San Francisco State University \\ Paul M. Wright \\ Northern Illinois University
}

The aim of this special issue is to celebrate Don Hellison's (1938-2018) life and legacy. From our earliest conversations about the organization and contents of this issue, we struggled with the task of dividing up such a rich, layered, and integrated tapestry. Certainly one thread in the tapestry is Don's biography, which was articulated by Jacobs and Templin (2020) in this issue ("The Man Behind the Teaching Personal and Social Responsibility Model: A Life History of Don Hellison"). However, it is difficult to tell that story without addressing the history of the Teaching Personal and Social Responsibility (TPSR) model that was crafted by Richards and Shiver (2020) in this issue ("'What's Worth Doing?': A Qualitative Historical Analysis of the TPSR Model"), along with the process of scholarship he used to develop it, as presented by Wright, Fuerniss, and Cutforth (2020; “Don Hellison's Scholarship Reconsidered"). We are pleased with the final product and extremely grateful to all of the contributing authors. In each article, the authors have pulled on a particular thread to help us appreciate, one aspect at a time, Don's life and legacy. As noted in the introduction, we believe each of these articles is a unique and important contribution in its own right. However, viewed as an integrated whole, we believe this special issue is an important product that conveys the fullness of Don's life and legacy. Rather than reiterating the important observations and insights shared by the various authors, we used the following paragraphs to pull back the focus with some concluding thoughts on the future of Don's work in three broad areasscholarship, policy, and practice. In each area, we have commented on the challenges and opportunities we see on the horizon.

\section{Scholarship}

We have seen a rapid expansion in scholarship related to the TPSR model. Don's reflective approach and his advocacy for servicebonded inquiry have left an indelible mark on the TPSR literature. Don himself encouraged the diversification of methods to answer new questions and continually improve on this approach. Recent trends in the literature indicate this will continue. Our hope is that the broad definition of scholarship that Don championed, including reflective approaches to discovery and community engagement, remains a strong anchor for this body of literature. We believe that we will see a continued commitment to practice-informing research, along with research-informing practice.

While Don and others made a strong case for service-bonded inquiry (Martinek \& Hellison, 1997; Martinek, Hellison, \& Walsh, 2004) and serve as role models, young scholars who wish to follow

Walsh is with San Francisco State University, San Francisco, CA, USA. Wright is with Northern Illinois University, DeKalb, IL, USA. Walsh (dwalsh@sfsu. edu) is corresponding author. in their footsteps may still find themselves fighting uphill. The ideal of balancing research and practice remains strong in the TPSR community, but many of us still have to "play the game" by generating enough of the right academic products to earn us the freedom to do more engaged work. Don's considerable talents, tenacity, and rebellious streak enabled him to carve out an enviable career. However, when Don moved from Portland State University to the University of Illinois at Chicago (UIC), he was hired as a full professor and had the freedom to be creative and invent programs in the surrounding underserved communities. Don did not have the pressure to earn tenure and promotion at UIC. He did not need to secure external funding for his research, and he was not pressured to publish data-driven articles, like his peers. He had a light teaching load and the time to develop the work he really cared about, with minimal external pressure. Today, most positions at Research 1 institutions such as UIC require a very different profile. So, advocating for continued growth and diversity in TPSR scholarship will also require support and advocacy for subsequent generations of scholars who need to navigate their own set of obstacles in order to be creative and innovative in their own right, while also meeting the external pressures imposed on them.

Few kinesiology departments have a strong emphasis on TPSR or sport-based youth development. What is more common is that a few readings and lectures are devoted to TPSR in the physical education teacher education programs. Because of the pressures of external accreditation and high-stakes licensure exams, these programs have little room for elective courses, alternative experiences, or nonessential topics. While Don's work has been held up as an exemplar by many sport psychologists, it is only tangential to their work. With little space in the curriculum for this type of work, there are few tenure track lines designed with this specialization in mind. Of the handful of professors nationally who have established TPSR as their major focus, most were hired within physical education teacher education or sport psychology programs. It is possible to thrive in such roles, but most of these individuals work in isolation at their institution. Junior faculty in this position may lack guidance or support in how to balance the requirements of their academic program, conduct publishable scholarship, and develop community outreach initiatives. We believe more senior TPSR scholars should be proactive in supporting and advocating for up-and-coming scholars to maintain these traditions.

\section{Policy}

Trends in physical education often follow the broader field of education, and both are influenced by societal needs and movements (Wright \& Walsh, 2015). As explained by Jacobs and Templin (2020) in this issue, Don's work spanned five decades that saw dramatic shifts in his field and in society. Currently, there is a surge 
of interest in social and emotional learning (Jacobs \& Wright, 2014). However, Don had been a champion for such outcomes long before educational research and policy brought them to the forefront. When he began his work, psychomotor skill development and fitness outcomes ruled the day. However, by the late 1990s, national content standards for physical education were established and included personally and socially responsible behavior (National Association for Sport and Physical Education, 1995, 2004; Society of Health and Physical Educators, 2014), clearly a sign of Don's influence. While these national standards created an opening for TPSR-related outcomes in the curriculum, they also reflected a broader national focus on standards-based performance and academic achievement. These trends, exemplified in the No Child Left Behind legislation, also gave primacy to the core curriculum and standardized testing. They played a large part in pushing physical education to the margins of the educational system (Amis, Wright, Dyson, Vardaman, \& Ferry, 2012). Is it a coincidence that these decades saw Don's most creative and innovative work occurring in out-of-school-time settings and affiliating more with the field of positive youth development, which was written about by Martinek and Hemphill (2020) in this issue ("The Evolution of Hellison's Teaching Personal and Social Responsibility Model in Out-ofSchool Contexts")?

Perhaps in response to its marginalized status, the field of physical education made a concerted effort to attach to the public health issues of childhood obesity and physical inactivity (McKenzie \& Lounsbery, 2013). Minutes spent in physical activity (or ideally moderate-to-vigorous physical activity) became the most prized outcome for many in the field of physical education. Through it all, whether his ideas were ignored, panned, or praised, Don's commitment and approach were not swayed.

It appears now that the winds have changed. With the Every Student Succeeds Act replacing No Child Left Behind, the federal government has shifted away from the idea of core subjects and moved toward emphasizing a well-rounded education. This creates additional space for physical education and the current surge of interest in social and emotional learning across the curriculum. Within physical education, TPSR is one of the leading best practices to address social and emotional learning in physical education (Jacobs \& Wright, 2014) and after-school programming (Gordon, Jacobs, \& Wright, 2016). The interest in TPSR is not restricted to the United States or to physical education. The United Nations Educational, Scientific and Cultural Organization (2019) recently released a curriculum for teaching sport values that is based in the TPSR model. Given the long years Don and his work were pushed to the margins (Hellison \& Martinek, 2008), the tide has certainly turned. We believe this external validation is well deserved and feel it is incumbent upon the TPSR community to capitalize on this moment to promote and expand this work in ways that honor Don and his legacy. At the same time, we realize such tides ebb and flow. Hopefully, the strength of our conviction will be similar to Don's if and when conditions shift again.

\section{Practice}

As explained by Dunn and Doolittle (2020) in this issue ("Professional Development for Teaching Personal and Social Responsibility: Past, Present, and Future"), Gloria Balague had the insight and motivation to push Don to cocreate the TPSR Alliance and host an annual conference. She was concerned for the future of his work as he was nearing the end of his career. Thanks to Gloria's foresight, there now exists a community of practice where scholars and practitioners can support each other as they try to both follow Don's example and chart their own way (Walsh $\&$ Wright, 2016). The TPSR Alliance has run a conference every summer since its inception in 2007, maintains a website, has coordinated several collaborative projects, and since 2018, has conferred the Don Hellison Award to a full-time teacher or youth worker who uses the TPSR model and exemplifies Don's values. We are confident this community of practice will continue to serve as an engine for the continuation of this important work.

Don emphasized the importance of continually working with kids, especially for folks who work at the university level. $\mathrm{He}$ believed that "being in the trenches" was important in order to create ideas and dialog about the TPSR model. After more than a decade of running the TPSR Alliance annual conference, it has become clear to us that various professionals will continue to contribute to the model in a variety of ways which was written about by Gordon and Beaudoin (2020) in this issue ("Expanding the Boundaries of TPSR and Empowering Others to Make Their Own Contributions"). Some are full-time teachers, coaches, and youth workers dedicated to proper implementation of the model with kids. Some university faculty members continue to work directly with kids and use these experiences to write about and inspire future teachers, youth workers, and scholars. Others are passionate about teaching the model to preservice teachers, although licensure requirements and program accreditation leave little room for deeper explorations. Some are dedicated to contributing to theory and conducting research on the effectiveness of the model. Others are helping to add the missing voices within the TPSR community, such as people of color and the lesbian, gay, bisexual, transgender, and queer or questioning community. This kind of diversity has the power to make change and contribute to our field and the broader community beyond what Don was able to do on his own. Our hope is that the future practice of the model will continue to evolve with new ideas, voices, and diversity while staying true to the essential values and goals that undergird it.

Obviously, Don's legacy and what we have learned about it in this special issue holds many lessons for those invested in the TPSR model. However, as Hans van der Mars (2020) illustrated in this issue ("Principled, Modest, and Giving ... Don Hellison's Impact Through the Eyes of His Peers"), Don's impact is not restricted to those who affiliate with the TPSR model. He inspired and befriended many who did different work and had different passions. Who he was as a person, how passionate he was in his beliefs, and how generous he was with his talents made him a role model for many in his life. We believe his example will endure for years to come, especially for those who ask the same sort of big questions, such as "What's worth doing?" With this in mind, we end this special issue with Don's own words from a viewpoint article he wrote late in his career. His parting questions and challenge capture his spirit and will resonate with us for years to come. "Are you wearing out your sword trying to make the right contributions? Not my contributions but ones that you own and cherish? My ultimate viewpoint is that all of us need to ask that question. Again and again" (Hellison, 2008, p. 9).

\section{References}

Amis, J., Wright, P.M., Dyson, B., Vardaman, J., \& Ferry, H. (2012). Implementing childhood obesity policy in a new educational environment: The cases of Mississippi and Tennessee. American Journal 
of Public Health, 102(7), 1406-1413. PubMed ID: 22420819 doi:10. 2105/AJPH.2011.300414

Dunn, R.J., \& Doolittle, S.A. (2020). Professional development for teaching personal and social responsibility: Past, present, and future. Journal of Teaching in Physical Education, 39(3). doi:10.1123/jtpe. 2019-0226

Gordon, B., \& Beaudoin, S. (2020). Expanding the boundaries of TPSR and empowering others to make their own contributions. Journal of Teaching in Physical Education, 39(3). doi:10.1123/jtpe.2019-0228

Gordon, B., Jacobs, J., \& Wright, P.M. (2016). Social and emotional learning through a teaching personal and social responsibility based after-school program designed for disengaged middle-school boys. Journal of Teaching in Physical Education, 35(2), 358-369. doi:10. 1123/jtpe.2016-0106

Hellison, D. (2008). This I believe about our field. Journal of Physical Education, Recreation \& Dance, 79(7), 6-9. doi:10.1080/07303084. 2008.10598205

Hellison, D., \& Martinek, T. (2008). Living in margins in our field. In L. Housner (Ed.), Teaching and research in physical education (pp. 265268). Washington, DC: National Association for Sport and Physical Education.

Jacobs, J.M., \& Templin, T. (2020). The man behind the teaching personal and social responsibility model: A life history of Don Hellison. Journal of Teaching in Physical Education, 39(3). doi:10.1123/ jtpe.2019-0220

Jacobs, J., \& Wright, P.M. (2014). Social and emotional learning policies and physical education. Strategies, 27(6), 42-44. doi:10.1080/ 08924562.2014 .960292

Martinek, T., \& Hellison, D. (1997). Service-bonded inquiry: The road less traveled. Journal of Teaching in Physical Education, 17(1), 107-121. doi:10.1123/jtpe.17.1.107

Martinek, T., Hellison, D., \& Walsh, D. (2004). Service-bonded inquiry revisited: A research model for the community-engaged professor. Quest, 56(4), 397-412. doi:10.1080/00336297.2004.10491833

Martinek, T., \& Hemphill, M.A. (2020). The evolution of Hellison's teaching personal and social responsibility model in out-of-school contexts. Journal of Teaching in Physical Education, 39(3). doi:10. 1123/jtpe.2019-0222

McKenzie, T.L., \& Lounsberry, M.A.F. (2013). Physical education teacher effectiveness in a public health context. Research Quarterly for Exercise and Sport, 84(4), 419-430. PubMed ID: 24592772 doi:10.1080/02701367.2013.844025

National Association for Sport and Physical Education. (1995). Moving into the future-National physical education standards: A guide to content and assessment. St. Louis, MO: Mosby Publishing.

Richards, K.A.R., \& Shiver, V.N. (2020). "What's worth doing?": A qualitative historical analysis of the TPSR model. Journal of Teaching in Physical Education, 39(3). doi:10.1123/jtpe.2019-0215

National Association for Sport and Physical Education. (2004). Moving into the future: National physical education standards (2nd ed.). Reston, VA: Author.

Society of Health and Physical Educators. (2014). National standards and grade-level outcomes for K-12 physical education (3rd ed.). Champaign, IL: Human Kinetics.

United Nations Educational, Scientific and Cultural Organization. (2019). Sport values in every classroom: Teacher's companion. Paris, France: Author.

Van der Mars, H. (2020). Principled, modest, and giving ... Don Hellison's impact through the eyes of his peers. Journal of Teaching in Physical Education, 39(3). doi:10.1123/jtpe.2019-0221

Walsh, D.S., \& Wright, P.M. (2016). The TPSR Alliance: An international community of practice for teaching, research and service. Journal of Physical Education, Recreation \& Dance, 87(5), 35-38. doi:10.1080/ 07303084.2016.1157394

Wright, P.M., Fuerniss, K., \& Cutforth, N. (2020). Don Hellison's scholarship reconsidered. Journal of Teaching in Physical Education, 39(3). doi:10.1123/jtpe.2019-0227

Wright, P.M., \& Walsh, D.S. (2015). Subject matter of physical education. In M.F. He, B.D. Schultz, \& W.H. Schubert (Eds.), The SAGE guide to curriculum in education. Los Angeles, CA: SAGE Publications. 